\title{
Correction to: Efficacy of phloroglucinol for the treatment of pain of gynaecologic or obstetrical origin: a systematic review of literature of randomised controlled trials
}

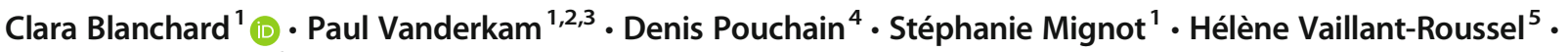 \\ Rémy Boussageon ${ }^{6}$
}

Published online: 23 November 2019

(C) Springer-Verlag GmbH Germany, part of Springer Nature 2019

\section{Correction to: European Journal of Clinical Pharmacology} https://doi.org/10.1007/s00228-019-02745-7

The correct presentation of the Author names are shown in this paper.

The online version of the original article can be found at https://oi.org/ $10.1007 / \mathrm{s} 00228-019-02745-7$

Clara Blanchard

Cla.blanchard@gmail.com

1 Department of General Medicine, University of Poitiers, 6 rue de la Milétrie, TSA 51115, 86073 Poitiers Cedex 9, France

2 Clinical Research Unit, Henri Laborit Hospital, 370 avenue Jacques Coeur, CS 10587, 86021 Poitiers, France

3 Laboratory of Experimental and Clinical Neurosciences, University of Poitiers, INSERM, U-1084, Poitiers, France

4 Department of General Medicine, University of Tours, 10 boulevard Tonnelé, 37032 Tours Cedex 1, France

5 Department of General Medicine and UPU ACCePPT, University of Auvergne, 18 place Henri Dunant, BP 38, 63001 Clermont-Ferrand, France

6 College of General Medicine, University of Lyon, 8 avenue Rockfeller, 69373 Lyon Cedex 08, France 